\title{
LAGARTA- FALSA-MEDIDEIRA, Pseudoplusia includens (WALKER, 1857), NOVA PRAGA DO MARACUJAZEIRO NO ESPÍRITO SANTO ${ }^{1}$
}

\author{
VERA LÚCIA RODRIGUES MACHADO BENASSI ${ }^{2}$, FABRÍCIO IGLESIAS VALENTE ${ }^{3}$, \\ EMERSON FRAGA COMÉRIO ${ }^{4}$, SIMÃO CARVALHO ${ }^{5}$
}

RESUMO - A espécie Pseudoplusia includens (Walker) (Lepidoptera: Noctuidae), lagarta-falsa-medideira, ataca diversas culturas de importância econômica, causando, na maioria das vezes, prejuízos consideráveis. Foram realizados levantamentos de todas as fases de desenvolvimento do inseto, no período de abril/2009 a abril/2010, em uma cultura de maracujá-azedo, Passifora edulis f. flavicarpa, no município de LinharesES, após ter sido constatada sua presença na área. A lagarta foi observada durante os meses de abril a novembro/2009 e de fevereiro a abril/2010, sendo constatados surtos mais severos nos meses de junho, setembro e novembro/2009, atingindo índices de até $80 \%$ de folhas danificadas. A planta invasora Solanum americanum (maria-pretinha), associada à cultura, é também hospedeira do inseto. Como inimigos naturais da lagarta, foram constatados o parasitoide Copidosoma truncatellum (Hymenoptera: Encyrtidae) e o entomopatógeno Baculovirus sp.. Este é o primeiro registro da ocorrência de $P$. includens na cultura de maracujá-azedo.

Termos para indexação: Lepidoptera, maracujá-amarelo, inimigo natural.

\section{THE LOOPER CATERPILLAR, Pseudoplusia includens (WALKER, 1857) NEW PEST OF YELLOW PASSION FRUIT CULTIVE IN ESPIRITO SANTO}

\begin{abstract}
The looper caterpillar, Pseudoplusia includens (Lepidoptera: Noctuidae) is a pest that attacks many economically important crops, causing, in most cases, considerable damage. Were conducted surveys of all stages of the insect development from April/2009 to April/2010 in a culture of yellow passion fruit, Passiflora f. Alavicarpa in Linhares, state of Espirito Santo, after noting its presence in the area. The caterpillar was observed during April to November/2009 and February to April/2010, however, the most severe outbreaks occurred in June, September and November/2009, reaching rates of up to $80 \%$ of leaves damaged. The weed Solanum americanum, is also a host of the insect. As natural enemies were observed the parasitoid Copidosoma truncatellum (Hymenoptera: Encyrtidae) and Baculovirus sp. entomopathogen. This is the first record of the occurrence of $P$. includens in cultivation of yellow passion fruit.
\end{abstract}

Index terms: Lepidoptera, passion fruit, natural enemy.

O Brasil é o maior consumidor e produtor mundial de maracujá, destacando-se o Estado da Bahia, seguido do Ceará, Espírito Santo, Sergipe e Minas Gerais. O Estado do Espírito Santo produziu, no ano de 2008, cerca de 66.396 toneladas de frutos, em uma área cultivada de 2.429 hectares (AGRIANUAL, 2011).

Como pragas da cultura, destacam-se a broca-do-maracujazeiro, percevejos, moscas-das-frutas, pulgões, vaquinhas e diversas espécies de lagartas desfolhadoras, sendo Dione juno juno, considerada praga-chave da cultura (MOURA et al., 2000).

A espécie Pseudoplusia includens ainda não foi relatada como praga da cultura do maracujá, entretanto são conhecidas como plantas hospedeiras de cerca de 73 espécies pertencentes a 29 famílias, destacando-se a soja, o algodoeiro, o feijoeiro, o fumo, o girassol e diversas hortaliças (HERZOG, 1980).

O inseto é conhecido como lagarta-falsa-medideira e pertence à família Noctuidae, subfamília Plusiinae, sendo que sua distribuição é restrita ao Hemisfério Ocidental, ocorrendo desde o norte dos Estados Unidos até o sul da América do Sul (ALFORD; HAMMOND, 1982)

Na cultura da soja, P. includens era conside-

\footnotetext{
${ }^{1}$ (Trabalho 018-12). Recebido em: 03-01-2012. Aceito para publicação em: 13-08-2012. Trabalho financiado pelo INCT HYMPAR SUDESTE/CNPq/FAPESP/CAPES.

2Doutora em Entomologia, INCAPER, Linhares, ES, vbenassi@incaper.es.gov.br

${ }^{3}$ Biólogo, Bolsista de Apoio Técnico/ INCT Hympar Sudeste/ CNPq, fabriciocbia@gmail.com

${ }^{4}$ Biólogo, Secretaria Municipal de Meio Ambiente e Recursos Hídricos Naturais/Linhares, emersoncomerio@hotmail.com

${ }^{5}$ Graduando, Bolsista de Apoio Técnico/ INCT Hympar Sudeste/ CNPq, simao.brasil@gmail.com
} 
rada uma praga secundária, controlada naturalmente por parasitoides e fungos entomopatogênicos, entretanto há alguns anos têm sido relatados surtos nos Estados de Mato Grosso do Sul, Goiás, São Paulo e Paraná (PAPA; CELOTO, 2011). De acordo com Sosa-Gómez et al. (2003), provavelmente as aplicações de fungicidas para o controle da ferrugem estejam contribuindo para a diminuição da incidência de fungos entomopatogênicos, como Nomuraea rileyi, e daqueles pertencentes ao grupo dos Entomophthorales, como Pandora sp., e Zoophthora sp. que mantinham a população do inseto em equilíbrio.

Para o controle da lagarta, são utilizados, basicamente, produtos químicos, os quais não têm sido eficientes em determinadas regiões brasileiras, devido ao seu hábito de permanecer na região inferior das folhas, o que dificulta que seja atingida (OLIVEIRA et al., 2010). Este fato faz com que sejam aumentadas as doses dos inseticidas, diminuindo a ação de seus inimigos naturais, além do aparecimento de populações resistentes aos produtos (MOLINA, 2007).

Os adultos de $P$. includens apresentam as asas anteriores de coloração marrom- acinzentada, com um pequeno desenho prateado semelhante à letra $\mathrm{Y}$, e medem cerca de $35 \mathrm{~mm}$ de envergadura. Os ovos, de coloração amarela, apresentam 31 a 33 estrias radiais e longitudinais e são colocados isoladamente na parte abaxial das folhas. As lagartas são verde-claras, com linhas longitudinais esbranquiçadas na região dorsal e três pares de pernas abdominais. Deslocam-se à semelhança das lagartas conhecidas como "mede-palmos" e, após o completo desenvolvimento, tecem um fino casulo de seda, no interior do qual transformam em pupa, tendo a princípio, a coloração verde-brilhante e, posteriormente, marrom-escura (GALLO et al., 2002).

O levantamento de $P$. includens foi realizado em um cultivo de maracujá-azedo,localizado no município de Linhares, Estado do Espírito Santo, após a constatação de ovos, lagartas e pupas presentes nas plantas, em abril/2009. A partir daí, foram realizadas coletas quinzenais até o mês de abril/2010.

As amostras foram transportadas ao Laboratório de Controle Biológico do Incaper, em Linhares-ES, e mantidos em recipientes para a observação de parasitoides e a obtenção de adultos, os quais foram enviados ao Prof. Dr. Sinval Silveira Neto, da ESALQ/USP, Piracicaba-SP, para a identificação da espécie.

A presença da lagarta em todas as fases de desenvolvimento foi observada no período de abril a outubro/2009 e de fevereiro a abril/2010, entretanto as maiores populações ocorreram nos meses de junho, agosto e novembro de 2009, atingindo índices de até $80 \%$ de folhas atacadas. As lagartas alimentam-se somente da epiderme das folhas do maracujá, que passam a apresentar um aspecto rendilhado, deixando as nervuras intactas. As regiões das folhas atacadas secam e, posteriormente, dão origem a orifícios.

Observações sobre as plantas invasoras presentes na área permitiram constatar a espécie Solanum americanum (Solanaceae), conhecida como maria-pretinha, hospedando ovos e lagartas de $P$. includens.

Como inimigos naturais, ocorreram o parasitoide Copidosoma truncatellum (Hymenoptera: Encyrtidae) e o entomopatógeno Baculovirus sp.. Os índices de parasitismo e de insetos doentes foram baixos, não reduzindo altas infestações da lagarta.

TABELA 1-Período de ocorrência de Pseudoplusia includens em cultivo de maracujá (Passiflora edulis f. flavicarpa) e na planta invasora maria-pretinha (Solanum americanum). Linhares-ES, 20092010.

\begin{tabular}{clcc}
\hline \multirow{2}{*}{ Período de coleta } & \multicolumn{2}{c}{ Plantas hospedeiras } \\
\cline { 2 - 4 } & Abril & Passiflora edulis f. flavicarpa & Solanum americanum \\
\hline & Maio & $\mathrm{x}$ & - \\
& Junho & $\mathrm{x}$ & - \\
& Julho & $\mathrm{x}$ & - \\
& Agosto & - & - \\
& Setembro & $\mathrm{x}$ & - \\
& Outubro & $\mathrm{x}$ & $\mathrm{x}$ \\
& Novembro & - & $\mathrm{x}$ \\
& Dezembro & $\mathrm{x}$ & - \\
& Janeiro & - & - \\
& Fevereiro & - & - \\
& Março & $\mathrm{x}$ & $\mathrm{x}$ \\
Abril & $\mathrm{x}$ & $\mathrm{x}$ \\
& & $\mathrm{x}$ & $\mathrm{x}$ \\
\hline
\end{tabular}




\section{REFERÊNCIAS}

AGRIANUAL: anuário da agricultura brasileira. Maracujá. São Paulo: FNP, Consultoria e Agroinformativos, 2011. p. 345.

ALFORD, A. R.; HAMMOND JUNIOR, A. N. Plusiinae (Lepidoptera: Noctuidae), populations in Louisiana soybeans ecosystems as determined with looplure-baited traps. Journal of Economic Entomology, Lanham, v.75, n. 4, p. 647-650, 1982.

GALLO, D.; NAKANO, O.; SILVEIRA NETO, S.; CARVALHO, R.P.L.; BATISTA, G.C. de; BERTI FILHO, E.; PARRA, J.R.P.; ZUCCHI, R.A.; ALVES, S.B.; VENDRAMIM, J. D.; MARCHINI, L.C.; LOPES, J.R.S.; OMOTO, C. Entomologia agrícola. Piracicaba: FEALQ, 2002. 920p.

HERZOG, D.C. Sampling soybean looper on soybean. In: KOGAN, M.; HERZOG, D.C. (Ed.). Sampling methods in soybean entomology. New York: Springer- Verlag, 1980. p.140-168.

MOLINA, A. Soja: expectativa x frustração. 2002. Disponível em: <www.embrapa.br/Famasul.htm>. Acesso em: 20 ago. 2011.
MOURA, F.L. de; PICANÇO, M.; GONRING, A.H.R.; BRUCKNER, C.H. Seletividade de inseticidas a três Vespidae predadores de Dione juno juno (Lepidoptera:Heliconidae). Pesquisa Agropecuária Brasileira, Brasília, v. 35, n.2, p. 251-257, 2000.

OLIVEIRA, J.R.G. di; FERREIRA, M. da C.; ROMÁN, R.A.A. Diferentes diâmetros de gotas e equipamentos para aplicação de inseticida no controle de Pseudoplusia includens. Engenharia Agrícola, Jaboticabal, v. 30, n.1, p. 92-99, 2010.

PAPA, G. CELOTO, F.J. Lagartas na soja. Disponível em: <http://www.ilhasolteira.com. $\mathrm{br} / \mathrm{colunas} /$ index $\cdot \mathrm{php}$ ?acao $=$ verartigo\&idarti go=1189090532>. Acesso em: 20 ago. 2011.

SOSA-GÓMEZ, D R; DELPIN K E; MOSCARDI F; NOZAKI M H. The impact of fungicides on Nomuraea rileyi (Farlow) Samson epizootics and on populations of Anticarsia gemmatalis Hübner (Lepidoptera: Noctuidae), on soybean. Neotropical Entomology, Londrina, v. 32, n.2, p. 287-291, 2003. 